\title{
Effects of dietary vitamin levels on physiological responses, blood profiles, and reproductive performance in gestating sows
}

\author{
Jae Hark Jeong, Jin Su Hong, Tae Hee Han, Lin Hu Fang, Woo Lim Chung and Yoo Yong Kim \\ Department of Agricultural Biotechnology, and Research Institute of Agriculture and Life Sciences, Seoul National University, Seoul 08826, Korea
}

\section{Abstract}

This study was performed to evaluate the effects of dietary vitamin levels on physiological responses, blood profiles, and reproductive performance in gestating sows. A total of $52 \mathrm{~F} 1$ multiparous sows (Yorkshire $\times$ Landrace) with an average body weight of $223.5 \pm 31.7 \mathrm{~kg}$, an average parity of $6.4 \pm 2.7$, and an average backfat thickness of $18.5 \pm 4.9 \mathrm{~mm}$ were divided into four treatment groups considering body weight, backfat thickness, and parity in a completely randomized design with 13 replicates. The treatments were $100 \%$ (V1), 300\% (V3), 600\% (V6) and 900\% (V9) of the National Research Council (NRC) Nutrient Requirements of Swine. The gestation diet was formulated based on corn-soybean meal (SBM) and contained 3,265 $\mathrm{kcal}$ of metabolizable energy (ME)/kg and $12.00 \%$ crude protein. During the lactation period, all sows were fed the same commercial lactation diet. There was no significant difference in body weight of gestating sows. However backfat thickness tended to increase when higher levels of vitamins were provided to gestating sows $(p<0.10)$. When high levels of dietary vitamins were provided, the body weight change of lactating sows increased $(p<0.01)$. When sows were fed higher levels of vitamins, the feed intake of lactating sows tended to decrease $(p=0.06)$. There were no treatment differences in the number of total born, born alive, stillbirth piglets, or the body weight of piglets according to different dietary vitamin level. As dietary vitamin level increased, the serum concentration of $25(\mathrm{OH}) \mathrm{D}_{3}$ in sows at 90 days of gestation linearly increased $(p<0.01)$. Furthermore, the serum vitamin $E$ level of gestating sows was linearly increased with increasing dietary vitamin level $(p<0.05)$. The current NRC vitamin requirements are sufficient for gestating sows and higher levels of vitamins in the gestation diet did not show any beneficial effects for gestating and lactating sows.

Keywords: Gestating sow, Litter performance, Reproductive performance, Serum vitamin concentration, Vitamin levels

\section{Background}

Vitamins are organic compounds required in only small quantities for normal growth, maintenance, and reproduction of animal life. Vitamin $\mathrm{D}_{3}$ is essential for the growth of, and maintenance of calcium and phosphorus homeostasis in, mammals [1]. In pigs, during gestation and lactation periods, vitamin $\mathrm{D}$ is required for calcium metabolism, to promote fetal growth and superior milk composition [2]. Vitamin E supplementation has been shown to increase the immunogenic capacity of reproductive sows [3], which is important for embryonic development and survival [4-6]. Vita$\min \mathrm{E}$ deficiency has been shown to affect reproduction in several animals, resulting in fetal death and resorption [7]. Therefore, a number of studies have been performed to estimate the vitamin

Received: Sept 2, 2019 Revised: Sept 4, 2019 Accepted: Sept 5, 2019

"Corresponding author: Yoo Yong Kim, Department of Agricultural Biotechnology, and Research Institute of Agriculture and Life Sciences, Seoul National University, Seoul 08826, Korea.

Tel: +82-2-880-4801, E-mail: yooykim@snu.ac.kr

This is an Open Access article distributed under the terms of the Creative Commons Attribution Non-Commercial License (http://creativecommons.org/licenses/by$\mathrm{nc} / 4.0 /$ ) which permits unrestricted non-commercial use, distribution, and reproduction in any medium, provided the original work is properly cited.

Copyright (C) 2019 Korean Society of Animal Science and Technology. 
requirements of pigs. Lindermann et al. [8] reported increasing trends of weight gain and feed intake in weanling pigs fed vitamins at levels five times higher than those suggested by the National Research Council (NRC) [9], but feed efficiency tended to be reduced with higher vitamin levels. Boyd et al. [10] reported that vitamin supplementation improved the litter size of sows. However, there have been few studies of the vitamin $\mathrm{D}$ requirements of sows during gestation or lactation [9].

Pig diets can be supplemented with a vitamin premix product in Korea to meet the requirements of the animals [11,12]. Flohr et al. [13] studied vitamins and minerals in the diet currently used in US swine farms, in a total of about 2,268,900 sows. They reported that pig producers added fat-soluble vitamins to the gestation diet at levels that were 2.6-, 2.2-, 1.6-, and 7.3-fold higher than the NRC requirements for vitamins A, D, E and K, respectively. Most feed companies in Korea supplement pig diets with vitamin premix at levels that are 3-10-fold higher than the NRC requirements [11]. The excessive vitamin supplementation of the diet of sows is responsible for the rising feed costs in Korea.

This study was performed to evaluate the effects of dietary vitamin levels on physiological responses, blood profiles, and reproductive performance in gestating sows.

\section{Materials and Methods}

\section{Animals}

All experimental procedures involving animals were performed in accordance with the Animal Experimental Guidelines of the Seoul National University Institutional Animal Care and Use Committee (SNUIACUC; SNU-160819-11). A total of 52 F1 multiparous sows (Yorkshire $\times$ Landrace) with an average body weight of $223.5 \pm 31.7 \mathrm{~kg}$, an average parity of $6.4 \pm 2.7$ and an av- erage backfat thickness of $18.5 \pm 4.9 \mathrm{~mm}$ were moved to individual gestation stalls for artificial insemination (AI). The sows were divided into one of four treatment groups according to body weight, backfat thickness, and parity in a completely randomized design with 13 replicates. They had twice-daily contact with a boar. AI was performed twice a day at 12-hour intervals with fresh diluted semen (Darby A.I. Center, Anseong, Korea) when signs of first estrus were detected. Pregnancy was checked at day 35 of gestation using an ultrasound scanner (Dongjin BLS, Gwangju, Korea).

\section{Experimental design and diet}

All experimental diets for gestating sows were based on corn-soybean meal (SBM) supplemented with vitamin premix at various levels; the treatments were 100\% (V1), 300\% (V3), 600\% (V6), and $900 \%$ (V9) of the NRC (2012) requirements.

Experimental vitamin premix was formulated to meet the NRC requirements (2012) when supplemented in the feed at $0.033 \%$. The vitamin premix formulas in the gestation diet are shown in Table 1. All experimental diets were supplemented with $0.1 \%$ choline chloride, and were formulated to contain $13.67 \mathrm{MJ}$ of metabolizable energy $/ \mathrm{kg}, 12.00 \%$ crude protein, $0.23 \%$ methionine, $0.74 \%$ lysine, $0.75 \%$ calcium, and $0.60 \%$ total phosphorus. All other nutrients were formulated to meet or exceed the NRC requirements (2012). Table 2 shows the formulas and chemical compositions of the experimental diets. All sows were fed the same commercial lactation diet during the lactation period.

\section{Animal management}

All experimental sows were fed the appropriate experimental diet once a day at around 08:00, and provided with $2.4 \mathrm{~kg} /$ day during gestation period. All sows were accommodated in individual gestation stalls $(2.20 \times 0.65 \mathrm{~m})$ and the temperature was maintained at

\section{Table 1. Formulas and concentrations of vitamin premix in gestation diets}

\begin{tabular}{lcc}
\hline & Vitamin requirements of the NRC (2012) & Concentration of vitamin in vitamin premix \\
\hline Vitamin $\mathrm{A}(\mathrm{IU} / \mathrm{kg})$ & 4,000 & 12,000 \\
Vitamin $\mathrm{D}_{3}(\mathrm{IU} / \mathrm{kg})$ & 800 & 2,400 \\
Vitamin $\mathrm{E}(50 \%)(\mathrm{IU} / \mathrm{kg})$ & 44 & 132 \\
Vitamin $\mathrm{K}($ menadione) $(\mathrm{mg} / \mathrm{kg})$ & 0.50 & 1.50 \\
Biotin $(2 \%)(\mathrm{mg} / \mathrm{kg})$ & 0.20 & 0.60 \\
Folacin $\left(\right.$ vitamin $\left.\mathrm{B}_{9}\right)(\mathrm{mg} / \mathrm{kg})$ & 1.30 & 3.90 \\
Niacin $(\mathrm{mg} / \mathrm{kg})$ & 10 & 30 \\
Calcium d-pantothenate $(\mathrm{mg} / \mathrm{kg})$ & 12 & 36 \\
Riboflavin $\left(\right.$ vitamin $\left.\mathrm{B}_{2}\right)(80 \%)(\mathrm{mg} / \mathrm{kg})$ & 3.75 & 11.25 \\
Thiamin $\left(\right.$ vitamin $\left.\mathrm{B}_{1}\right)(98 \%)(\mathrm{mg} / \mathrm{kg})$ & 1.00 & 3.00 \\
Vitamin $\mathrm{B}_{6}(100 \%)(\mathrm{mg} / \mathrm{kg})$ & 1.00 & 3.00 \\
Vitamin $\mathrm{B}_{12}(1 \%)(\mu \mathrm{g} / \mathrm{kg})$ & 15 & 45 \\
\hline
\end{tabular}

NRC, National Research Council. 
Table 2. Formulas and chemical compositions of gestation diets

\begin{tabular}{|c|c|c|c|c|}
\hline \multirow{2}{*}{ Item } & \multicolumn{4}{|c|}{ Gestation diet ${ }^{1)}$} \\
\hline & V1 & V3 & V6 & V9 \\
\hline \multicolumn{5}{|l|}{ Ingredients (\%) } \\
\hline Corn & 76.897 & 76.77 & 76.58 & 76.38 \\
\hline Soybean meal-46 & 11.97 & 11.99 & 12.02 & 12.05 \\
\hline Wheat bran & 6.00 & 6.00 & 6.00 & 6.00 \\
\hline Tallow & 1.75 & 1.79 & 1.85 & 1.92 \\
\hline L-lysine $\mathrm{HCl}(78 \%)$ & 0.26 & 0.26 & 0.26 & 0.26 \\
\hline DL-methionine (99\%) & 0.04 & 0.04 & 0.04 & 0.04 \\
\hline DCP & 1.35 & 1.35 & 1.35 & 1.35 \\
\hline Limestone & 1.20 & 1.20 & 1.20 & 1.20 \\
\hline Vit. premix ${ }^{2)}$ & 0.033 & 0.10 & 0.20 & 0.30 \\
\hline Min. premix $x^{3)}$ & 0.10 & 0.10 & 0.10 & 0.10 \\
\hline Choline chloride- 50 & 0.10 & 0.10 & 0.10 & 0.10 \\
\hline Salt & 0.30 & 0.30 & 0.30 & 0.30 \\
\hline Total & 100.00 & 100.00 & 100.00 & 100.00 \\
\hline \multicolumn{5}{|l|}{ Chemical composition ${ }^{4)}$} \\
\hline ME (MJ/kg) & 13.67 & 13.67 & 13.67 & 13.67 \\
\hline Crude protein (\%) & 12.00 & 12.00 & 12.00 & 12.00 \\
\hline Total lysine (\%) & 0.74 & 0.74 & 0.74 & 0.74 \\
\hline Total methionine (\%) & 0.23 & 0.23 & 0.23 & 0.23 \\
\hline Calcium (\%) & 0.75 & 0.75 & 0.75 & 0.75 \\
\hline Total phosphorus (\%) & 0.60 & 0.60 & 0.60 & 0.60 \\
\hline
\end{tabular}

${ }^{11}$ Treatment: V1, corn-soybean meal (SBM)-based diet with 1× National Research Council (NRC, 2012) vitamin requirement; V3, corn-SBM-based diet with $3 \times$ NRC (2012) vitamin requirement; V6, corn-SBM-based diet with $6 \times$ NRC (2012) vitamin requirement; V9, corn-SBM-based diet with $9 \times$ NRC (2012) vitamin requirement.

${ }^{2)}$ Provided per kg of diet: vitamin $\mathrm{A}, 12,000 \mathrm{IU}$; vitamin $\mathrm{D}_{3}, 2,400 \mathrm{IU}$; vitamin E, $132 \mathrm{IU}$; vitamin $\mathrm{K}, 1.5 \mathrm{mg}$; biotin, $0.60 \mathrm{mg}$; folacin, $3.9 \mathrm{mg}$; niacin, $30 \mathrm{mg}$; calcium pantothenic acid, $36 \mathrm{mg}$; thiamin, $3 \mathrm{mg}$; vitamin $\mathrm{B}_{6}, 3 \mathrm{mg}$; vitamin $\mathrm{B}_{12}, 45 \mathrm{~g}$.

${ }^{3)}$ Provided per kg of diet: Se, 0.3 mg; l, 0.3 mg; Mn, 49 mg; Cu, 288 mg; Fe, 281 mg; $\mathrm{Zn}, 84.7 \mathrm{mg}$; Co, $0.3 \mathrm{mg}$.

${ }^{4)}$ Calculated value.

DCP, digestible crude protein; ME, metabolizable energy.

an average of $20^{\circ} \mathrm{C}$ by an automated ventilation system. Pregnant sows were washed and moved into farrowing crates $(2.40 \times 1.80 \mathrm{~m})$ on day 110 of gestation and the gestation diet was decreased gradually by $0.2 \mathrm{~kg}$ per day over the 5 days before farrowing. Delivery inducer was not used during farrowing and assistance was provided in all cases of dystocia. After farrowing, the lactation diet was increased gradually from $1.0 \mathrm{~kg} /$ day until 5 days postpartum, and then provided ad libitum during the lactation period. Each farrowing crate was equipped with a feeder and a nipple waterer for sows, and a heat lamp for newborn piglets. The temperature of the lactation barn was kept at $28^{\circ} \mathrm{C} \pm 2{ }^{\circ} \mathrm{C}$ and the piglet area was maintained at $32^{\circ} \mathrm{C} \pm 2{ }^{\circ} \mathrm{C}$ under a heating lamp. The air condition in the lactation barn was regulated automatically by a ventilation system and air-conditioner. Piglets were cross-fostered within treatment groups until 24 hours postpartum, to balance the suckling intensity of sows with litter size, and thus to minimize any potential effect of initial litter size on litter growth. Cutting of the umbilical cord and tail and castration were performed 3 days after birth, and piglets were injected with 150 ppm Fe-dextran (Gleptosi ${ }^{\circledR}$; Alstoe, York, UK). None of the piglets were fed creep feed during the whole lactation period. Weaning was performed at approximately 21 days after birth.

\section{Body weight, backfat thickness, lactation feed intake}

The live body weight and backfat thickness of sows were recorded at mating, at 70, 90, and 110 days of gestation, at 24 hours postpartum, and at 21 days of lactation, respectively. The body weight of sows was measured using an electronic scale (CAS Co. Ltd., Yangju-si, Gyeonggi-do, Korea) and backfat thickness was measured using an ultrasound device (Lean Meter ${ }^{\circledR}$; Renco Corp., Minneapolis, MN, USA) at the $\mathrm{P} 2$ position (mean value from both sides of the last rib and $65 \mathrm{~mm}$ from the backbone). Daily feed wastage was recorded during the lactation period, and lactation feed intake was estimated for 21 days to determine the physiological effects on sows.

\section{Reproductive performance}

The reproductive traits were recorded within 24 hours postpartum, including total number of piglets, number of piglets born alive, stillbirths, and piglet losses. Individual piglet weights (born and stillbirth) were measured at birth and 21 days of lactation using an electronic scale (CAS Co. Ltd.). Ear notching was performed when measuring the body weight of the piglets. The average daily weight gain of the piglets was calculated to determine their growth and lactation performance after farrowing. The weaning to estrus interval (WEI) of sows, as an important parameter for evaluating reproductive performance, was measured after weaning.

\section{Blood profiles}

Blood samples ( $\mathrm{n}=4$ for each treatment) were collected from the jugular vein of sows using $10-\mathrm{mL}$ disposable syringes at mating, days 70,90 , and 110 of gestation, 24 hours postpartum, and 21 days of lactation. In addition, blood samples were collected from the anterior vena cava of piglets using 3-mL disposable syringes at 24 hours postpartum, and 5-mL disposable syringes at 21 days of lactation. All blood samples were collected into serum tubes (BD Vacutainer SST ${ }^{\mathrm{TM}}$ II Advance; Becton Dickinson, Plymouth, UK) and EDTA tubes (BD Vacutainer K2E; Becton Dickinson). Individual samples were centrifuged at $2,515 \times \mathrm{g}, 4^{\circ} \mathrm{C}$ for 15 minutes (5810R; Eppendorf, Hamburg, Germany) and the supernatants were separated into microtubes (Axygen, Union City, CA, USA) and stored at $-20^{\circ} \mathrm{C}$ until analysis. 
Serum 25-(OH)-vitamin D was analyzed by chemiluminescence immunoassay (CIA) (Liaison; DiaSorin, Cypress, CA, USA), vitamin $\mathrm{E}$ by high-performance liquid chromatography (HPLC) (HPLC-UVD; Waters Corporation, Milford, MA, USA), calcium by colorimetry (Hitachi, Tokyo, Japan), and inorganic phosphorus by UV spectrophotometry (Roche Diagnostics, Penzberg, Germany).

\section{Statistical analysis}

All data were analyzed by analysis of variance (ANOVA) in a completely randomized design using the GLM procedure in SAS software (ver.; SAS Institute, Cary, NC, USA). Orthogonal polynomial contrast was used to determine linear and quadratic effects according to increases in the vitamin levels of the gestation diets of sows and piglets. Individual sows and their litters were used as the experimental unit for analyses of growth performance, reproductive performance and blood profile. Differences among means were taken to be significant at $p<0.05$ and highly significant at $p<0.01$, with trends being between $p \geq 0.05$ and $p<0.10$. When significance was detected, Fisher's least significant difference (LSD) test was applied for post hoc analysis.

\section{Results and Discussion}

\section{Body weight, backfat thickness of gestating sows}

The effects of different levels of vitamin supplementation on the body weight and backfat thickness of sows during the gestation period are shown in Table 3. There were no significant group differences in terms of the body weight of gestating sows at any time point examined. Sows fed higher levels of vitamins tended to show increased backfat thickness, both at 90 days of gestation and over the whole gestation period (linear, $p=0.067, p=0.081$, respectively). Lauridsen et al. [14] reported no differences in body weight change during the first 28 days of gestation in gilts fed diets varying in vitamin $\mathrm{D}$ (vitamin $\mathrm{D}_{3}$ or $25-(\mathrm{OH})$-vitamin $\mathrm{D}$ ) level (200, 800, 1,400, or $2,000 \mathrm{IU} / \mathrm{kg}$ of diet). Similarly, vitamin $\mathrm{D}_{3}$ supplementation (concentrations between 1,500 and 6,000 IU/kg) of the complete diet had no influence on sow body weight change or average daily feed intake (ADFI) during the lactation period [15]. Mahan [16] reported that dietary vitamin E level had no effect on the body weight of sows given diets supplemented with vitamin $\mathrm{E}(22,44$, or $66 \mathrm{IU} / \mathrm{kg}$ of diet) during the gestation and lactation periods. In the present study, no significant difference was observed in the body weight of gestating sows fed diets containing vitamins $\mathrm{D}$ and $\mathrm{E}$ at various concentrations $(800,2,400,4,800$, or $7,200 \mathrm{IU} / \mathrm{kg}$ of diet and 44, 132, 264, or $396 \mathrm{IU} / \mathrm{kg}$ of diet, respectively). Mahan [16] reported no significant differences in backfat thickness at 109 days post coitum or weaning between sows fed different levels of vitamin E. In addition, Lauridsen et al. [14] reported that vitamin $\mathrm{D}$ dose had no influence on backfat thickness in sows. Shelton et al. [17] observed no differences in sow body weight or backfat thickness during the entire period from gestation to lactation, when sows were fed diets supplemented with vitamin $\mathrm{E}$ at four levels (11,22,33, or $44 \mathrm{IU} / \mathrm{kg}$ of diet).

\section{Body weight, backfat thickness, daily feed intake and WEI of lactating sows}

The effects of different vitamin levels in the diet during the ges-

Table 3. Effects of vitamin supplementation levels in gestation diets on growth performance during gestation

\begin{tabular}{|c|c|c|c|c|c|c|c|}
\hline & \multicolumn{4}{|c|}{ Treatment $^{1)}$} & \multirow{2}{*}{ SEM } & \multicolumn{2}{|c|}{$p$-value } \\
\hline & V1 & V3 & V6 & V9 & & Lin. & Quad. \\
\hline \multicolumn{8}{|l|}{ Body weight (kg) } \\
\hline At mating & 223.76 & 223.23 & 223.73 & 223.23 & 4.388 & 0.978 & 0.998 \\
\hline 70 days & 250.54 & 242.77 & 241.95 & 243.87 & 3.899 & 0.576 & 0.549 \\
\hline 90 days & 259.04 & 252.05 & 253.00 & 254.14 & 3.878 & 0.711 & 0.616 \\
\hline 110 days & 269.69 & 267.59 & 267.21 & 268.68 & 4.157 & 0.932 & 0.838 \\
\hline BW gain (0-110 days) & 45.90 & 44.36 & 43.48 & 45.45 & 1.455 & 0.101 & 0.965 \\
\hline \multicolumn{8}{|l|}{ Backfat thickness (mm) } \\
\hline At mating & 18.65 & 18.35 & 18.46 & 18.46 & 0.674 & 0.941 & 0.912 \\
\hline 70 days & 20.35 & 22.70 & 21.04 & 23.14 & 0.899 & 0.432 & 0.943 \\
\hline 90 days & 21.15 & 23.32 & 23.00 & 26.80 & 0.971 & 0.067 & 0.673 \\
\hline 110 days & 22.50 & 22.95 & 24.32 & 26.60 & 0.960 & 0.129 & 0.639 \\
\hline BF gain (0-110 days) & 3.85 & 4.60 & 5.86 & 8.14 & 0.533 & 0.081 & 0.165 \\
\hline
\end{tabular}

${ }^{1 T}$ Treatment: V1, corn-soybean meal (SBM) based diet with 1× National Research Council (NRC, 2012) vitamin requirement; V3, corn-SBM-based diet with 3× NRC (2012) vitamin requirement; V6, corn-SBM-based diet with 6× NRC (2012) vitamin requirement; V9, corn-SBM-based diet with 9× NRC (2012) vitamin requirement. Lin., linear; Quad., quadratic; BW, body weight; BF, backfat thickness. 
tation period on body weight, backfat thickness, daily feed intake, and WEI during the lactation period are presented in Table 4. There were no significant differences in body weight at 24 hours postpartum or 21 days of lactation among the treatment groups. On the other hand, the body weight change of lactating sows was increased when they were provided with diets with higher vitamin levels during the gestation period (linear, $p=0.027$ ). There was no significant difference in backfat thickness at 24 hours postpartum or 21 days of lactation among the treatment groups. The feed intake of lactating sows tended to decrease with increasing vitamin levels in the diet (linear, $p=0.06$ ). After weaning, the WEI showed a quadratic response as the vitamin supplementation level was increased (quadratic, $p=0.047$ ), although there was no significant difference among the treatment groups. Flohr et al. [15] reported no difference in $\mathrm{ADFI}$ during the lactation period among groups with vitamin $\mathrm{D}_{3}$ supplementation between 1,500 and 6,000 IU/ $\mathrm{kg}$ of the complete diet. In addition, Shelton et al. [17] reported no difference in total or daily feed intake during the lactation period when sows were fed diets supplemented with vitamin $\mathrm{E}$ at four levels, i.e., $11,22,33$, and $44 \mathrm{IU} / \mathrm{kg}$ of diet, during the gestation and lactation periods. On the other hand, Lauridsen et al. [14] reported greater $\mathrm{ADFI}$ in lactating sows when they were fed the lowest dose of vitamin D (200 IU/kg of diet). However, they could not draw conclusions from the results because number of lactation days and the total feed intake were affected by the form and dose of vitamin D. In agreement with the above results, the present study indicated that the ADFI of lactation sows decreased with increasing levels of vitamin supplementation.

Lauridsen et al. [14] reported that the body weight of sows at weaning was different between groups receiving dietary vitamin D doses of 200, 800, 1,400, and 2,000 IU/ $\mathrm{kg}$ of diet. Flohr et al.
[15] reported that the vitamin $\mathrm{D}_{3}$ level in the diet did not affect the body weight of lactating sows at weaning. However, Mahan [16] reported that sow weight loss during the period of lactation increased with increasing dietary vitamin $\mathrm{E}$ level. However, they could not explain the weight loss in the sows. Several studies suggested that obese individuals tend to have low serum levels of $25(\mathrm{OH}) \mathrm{D}_{3}[18,19]$. However, recent studies suggested that adipose tissue could be a direct target of vitamin $\mathrm{D}$, and that the hormone could control the formation and function of adipose tissue [20,21]. Therefore, the low serum levels of $25(\mathrm{OH}) \mathrm{D}_{3}$ in obese individuals may be due to greater isolation by adipose tissue [22,23].

Vitamin D can act through numerous non-genomic mechanisms such as protein expression, inflammation, oxidative stress, and cellular metabolism [24]. In addition, Ding et al. (2012) reported a signaling role of vitamin $\mathrm{D}$ in adipocytes, and discussed the potential mechanisms for vitamin D to affect tissue development and function. These findings suggested that vitamin $\mathrm{D}$ may have played a role in increasing the backfat thickness of the sows in the present study. Greater backfat thickness at farrowing is associated with lower lactation feed intake [25,26]. The effects of body fat content on voluntary lactation feed intake were reported to involve several mechanisms, including turnover of body fat tissue [27], insulin and leptin levels in blood [28], and milk production [29,30]. These mechanisms explain the reductions of feed intake and body weight during the lactation period observed in the present study.

\section{Reproductive performance of sows and litter performance} The effects of different levels of vitamins in the gestation diet on the reproductive performance of sows and litter performance are presented in Table 5. There were no significant differences in the numbers of total born, born alive, or stillborn piglets among sows

Table 4. Effects of vitamin supplementation levels in gestation diets on growth performance of sows during lactation

\begin{tabular}{|c|c|c|c|c|c|c|c|}
\hline & \multicolumn{4}{|c|}{ Treatment $^{1)}$} & \multirow{2}{*}{ SEM } & \multicolumn{2}{|c|}{$p$-value } \\
\hline & V1 & V3 & V6 & V9 & & Lin. & Quad. \\
\hline \multicolumn{8}{|l|}{ Body weight (kg) } \\
\hline 24 hours postpartum & 246.99 & 247.81 & 245.65 & 243.01 & 4.252 & 0.735 & 0.847 \\
\hline 21 day of lactation & 241.67 & 235.40 & 237.32 & 223.46 & 4.221 & 0.194 & 0.660 \\
\hline BW changes $(0-21 \mathrm{~d})$ & -5.32 & -12.41 & -10.91 & -19.55 & 1.909 & 0.027 & 0.570 \\
\hline \multicolumn{8}{|l|}{ Backfat thickness (mm) } \\
\hline 24 hours postpartum & 20.33 & 21.27 & 23.35 & 20.33 & 1.161 & 0.830 & 0.375 \\
\hline 21 day of lactation & 19.11 & 21.91 & 20.32 & 20.33 & 0.946 & 0.739 & 0.653 \\
\hline 24 hours postpartum & -1.22 & -0.64 & -3.03 & -0.00 & 0.503 & 0.881 & 0.197 \\
\hline ADFI (kg) & 5.05 & 4.90 & 4.87 & 4.21 & 0.143 & 0.060 & 0.375 \\
\hline WEl (day) & 4.81 & 5.89 & 5.07 & 4.67 & 0.189 & 0.447 & 0.047 \\
\hline
\end{tabular}

${ }^{1 T}$ Treatment: V1, corn-soybean meal (SBM) based diet with 1× National Research Council (NRC, 2012) vitamin requirement; V3, corn-SBM-based diet with 3× NRC (2012) vitamin requirement; V6, corn-SBM-based diet with 6× NRC (2012) vitamin requirement; V9, corn-SBM-based diet with 9× NRC (2012) vitamin requirement. Lin., linear; Quad., quadratic; BW, body weight; $\mathrm{ADFI}$, average daily feed intake; $\mathrm{WEI}$, weaning to estrus interval. 
Table 5. Effects of vitamin supplementation levels in gestation diets on reproductive performance of gestating sows

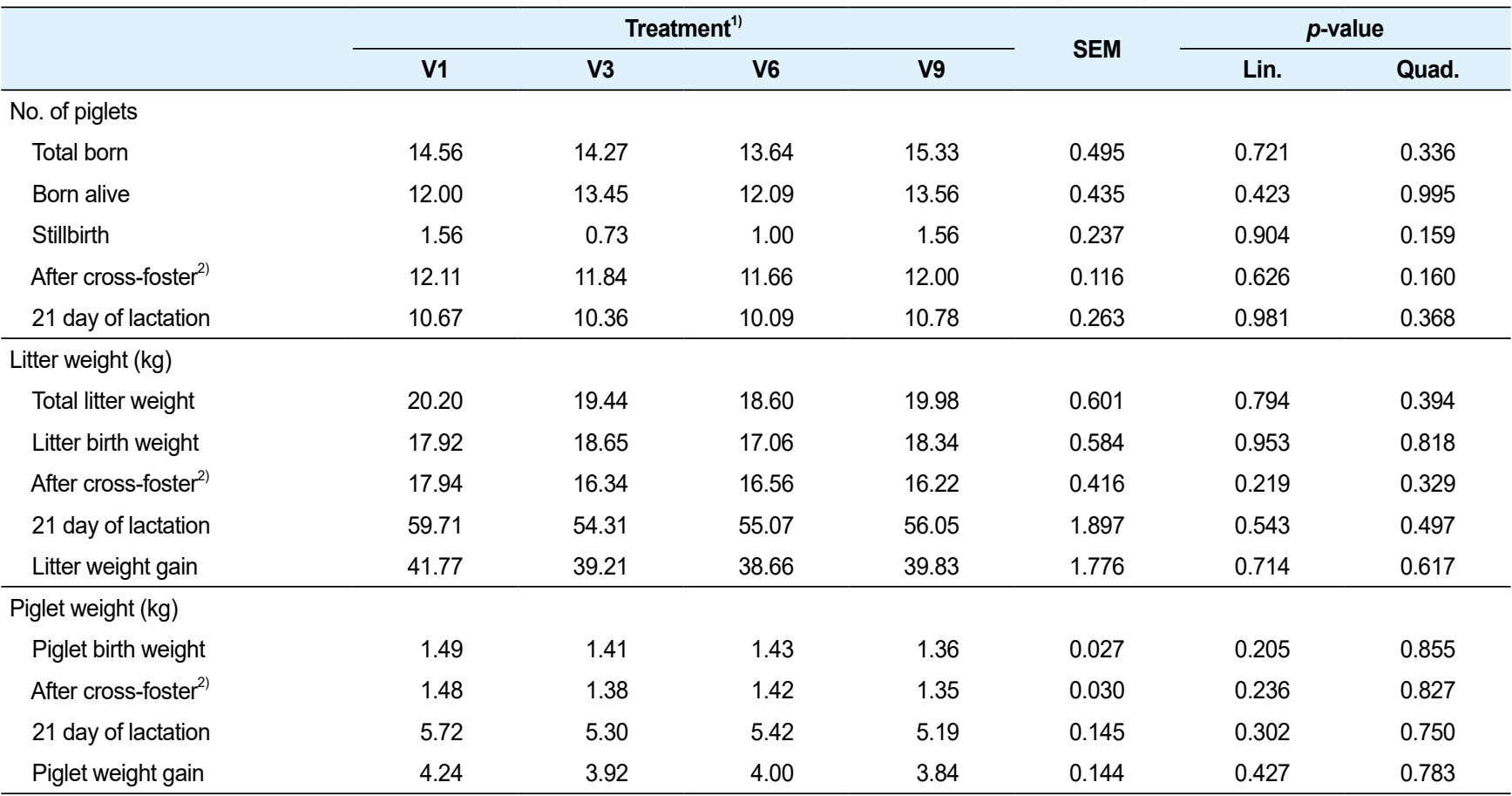

${ }^{11}$ Treatment: V1, corn-soybean meal (SBM) based diet with 1× National Research Council (NRC, 2012) vitamin requirement; V3, corn-SBM-based diet with 3× NRC (2012) vitamin requirement; V6, corn-SBM-based diet with 6× NRC (2012) vitamin requirement; V9, corn-SBM-based diet with 9× NRC (2012) vitamin requirement.

${ }^{2)}$ After cross-fostering day within 24 hours postpartum.

Lin., linear; Quad., quadratic.

fed diets containing different vitamin levels. In addition, the different dietary vitamin levels showed no effects on total litter weight, litter birth weight, or litter weight at 21 days of lactation. Lauridsen et al. [14] reported that the number of stillborn piglets decreased with vitamin $\mathrm{D}_{3}$ levels of 1,400 and 2,000 IU compared to 200 and 800 IU. They reported that the performance of the litter from birth to weaning was not influenced by the dietary vitamin D level, but the litter body weight after 2 weeks was increased by increasing the dose of vitamin D. Flohr et al. [15] reported that the levels of maternal vitamin $\mathrm{D}_{3}$ did not affect litter size, mummies, stillbirths, number of piglets born alive, number of weaning pigs, or suckling pig performance. Similarly, no differences were observed in litter size, average weight, or total litter weight according to the level of vitamin E supplementation [17]. Several studies have indicated that the supplementation of the diet with $30-60 \mathrm{IU} / \mathrm{kg}$ of vitamin $E$ is sufficient to optimize reproductive performance of pigs [16,31].

\section{Blood profiles}

There were no significant differences in the serum levels of 25- $(\mathrm{OH})$-vitamin $\mathrm{D}$ or vitamin $\mathrm{E}$ in the blood of gestating sows according to the level of vitamin in the diet (Table 6). However, the serum $25(\mathrm{OH}) \mathrm{D}_{3}$ concentration in sows at 90 days of gestation increased linearly with increasing dietary vitamin level (linear, $p=0.003$ ). Furthermore, the serum vitamin $\mathrm{E}$ level of sows during gestation increased linearly with increasing dietary vitamin level $(p$ $<0.05)$. There were no significant differences in serum phosphorus concentrations among sows fed diets with different levels of vitamin supplementation (Table 7). On the other hand, the calcium concentration at 70 days of gestation was significantly elevated in sows fed a diet containing three times the NRC (2012)-recommended vitamin level. In addition, the calcium concentration tended to increase with increasing vitamin supplementation level at 70 and 110 days of gestation (linear, $p=0.067, p=0.077$, respectively). The effects of vitamin supplementation level of the gestation diet on the blood profiles of sows and piglets during the lactation period are shown in Tables 8 and 9, respectively. Vitamin supplementation levels had no effect on the blood profiles of sows. However, significant differences were observed in the concentrations of $25-(\mathrm{OH})$-vitamin $\mathrm{D}$ in piglets at 24 hours postpartum and day 21 of lactation $(p<0.05)$. The concentration of $25-(\mathrm{OH})$-vita$\min \mathrm{D}$ increased linearly in piglets at 21 days of lactation when the vitamin level was increased in the diet of sows (linear, $p=0.011$ ). Significant differences were observed in vitamin $\mathrm{E}$ levels according to the vitamin supplementation level. The concentration of vitamin E in the blood of sows fed the NRC (2012) vitamin requirement, i.e., $44 \mathrm{IU}$ of vitamin $\mathrm{E} / \mathrm{kg}$ of diet, was significantly lower than in the other treatment groups $(p<0.01)$. In addition, the serum concentration of vitamin $\mathrm{E}$ in sows increased with increasing dietary 
Table 6. Effects of vitamin supplementation levels in gestation diets on serum vitamin concentrations of sows during the gestation period

\begin{tabular}{|c|c|c|c|c|c|c|c|}
\hline & \multicolumn{4}{|c|}{ Treatment $^{1)}$} & \multirow{2}{*}{ SEM } & \multicolumn{2}{|c|}{$p$-value } \\
\hline & V1 & V3 & V6 & V9 & & Lin. & Quad. \\
\hline \multicolumn{8}{|c|}{$25-(\mathrm{OH})$ vitamin $\mathrm{D}(\mathrm{ng} / \mathrm{mL})$} \\
\hline Initial & - & - & & 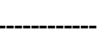 & & & \\
\hline 14 days & 102.0 & 85.6 & 103.6 & 102.4 & 4.81 & 0.669 & 0.454 \\
\hline 28 days & 123.0 & 96.6 & 124.3 & 133.0 & 5.97 & 0.255 & 0.129 \\
\hline 70 days & 125.3 & 137.0 & 142.7 & 150.0 & 5.02 & 0.109 & 0.832 \\
\hline 90 days & 106.0 & 115.9 & 149.7 & 157.1 & 7.11 & 0.003 & 0.596 \\
\hline 110 days & 134.3 & 133.5 & 136.3 & 166.2 & 3.75 & 0.136 & 0.476 \\
\hline \multicolumn{8}{|c|}{ Vitamin E (Tocopherol) ( $\mu \mathrm{mol} / \mathrm{L})$} \\
\hline Initial & - & - & - & - & & & \\
\hline 14 days & 4.3 & 3.7 & 4.4 & 4.3 & 0.23 & 0.719 & 0.616 \\
\hline 28 days & 8.4 & 8.5 & 12.2 & 13.0 & 0.81 & 0.012 & 0.783 \\
\hline 70 days & 7.9 & 9.8 & 11.7 & 10.9 & 0.92 & 0.236 & 0.511 \\
\hline 90 days & 12.2 & 13.9 & 18.9 & 20.2 & 1.35 & 0.015 & 0.945 \\
\hline 110 days & $9.6^{\mathrm{B}}$ & $12.7^{\mathrm{A}}$ & $13.8^{\mathrm{A}}$ & $14.6^{\mathrm{A}}$ & 0.97 & 0.013 & 0.297 \\
\hline
\end{tabular}

${ }^{1)}$ Treatment: V1, corn-soybean meal (SBM)-based diet with 1× National Research Council (NRC, 2012) vitamin requirement; V3, corn-SBM-based diet with 3× NRC (2012) vitamin requirement; V6, corn-SBM-based diet with 6× NRC (2012) vitamin requirement; V9, corn-SBM-based diet with 9× NRC (2012) vitamin requirement.

${ }^{A, B}$ Means with different capital letter superscripts in the same row are significantly different $(p<0.01)$.

Lin., linear; Quad., quadratic.

Table 7. Effects of vitamin supplementation levels in gestation diets on serum calcium and phosphorus level during the gestation period

\begin{tabular}{|c|c|c|c|c|c|c|c|}
\hline & \multicolumn{4}{|c|}{ Treatment $^{1)}$} & \multirow{2}{*}{ SEM } & \multicolumn{2}{|c|}{$p$-value } \\
\hline & V1 & V3 & V6 & V9 & & Lin. & Quad. \\
\hline \multicolumn{8}{|c|}{ Calcium (mg/dL) } \\
\hline Initial & ----- & 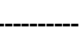 & -1- & 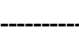 & & & \\
\hline 14 days & 9.9 & 9.6 & 10.0 & 10.0 & 0.09 & 0.349 & 0.348 \\
\hline 28 days & 9.8 & 9.9 & 10.0 & 10.0 & 0.08 & 0.451 & 0.671 \\
\hline 70 days & $9.8^{\mathrm{ab}}$ & $10.0^{\mathrm{a}}$ & $9.8^{\mathrm{ab}}$ & $9.5^{\mathrm{b}}$ & 0.06 & 0.067 & 0.019 \\
\hline 90 days & 9.3 & 9.4 & 9.1 & 9.6 & 0.09 & 0.479 & 0.240 \\
\hline 110 days & 9.4 & 9.6 & 9.4 & 10.1 & 0.11 & 0.077 & 0.391 \\
\hline \multicolumn{8}{|c|}{ Inorganic phosphorus (mg/dL) } \\
\hline \multicolumn{8}{|l|}{ Initial } \\
\hline 14 days & 6.0 & 6.1 & 5.8 & 6.2 & 0.14 & 0.914 & 0.629 \\
\hline 28 days & 6.2 & 6.5 & 6.3 & 6.9 & 0.14 & 0.112 & 0.612 \\
\hline 70 days & 5.9 & 5.9 & 6.1 & 5.7 & 0.10 & 0.756 & 0.330 \\
\hline 90 days & 5.6 & 5.7 & 5.9 & 5.6 & 0.17 & 0.985 & 0.589 \\
\hline 110 days & 7.3 & 6.6 & 6.7 & 7.7 & 0.18 & 0.269 & 0.020 \\
\hline
\end{tabular}

${ }^{1)}$ Treatment: V1, corn-soybean meal (SBM) based diet with 1× National Research Council (NRC, 2012) vitamin requirement; V3, corn-SBM-based diet with 3× NRC (2012) vitamin requirement; V6, corn-SBM-based diet with 6× NRC (2012) vitamin requirement; V9, corn-SBM-based diet with 9× NRC (2012) vitamin requirement.

${ }^{a, b}$ Means with different small letter superscripts in the same row are significantly different $(p<0.05)$.

Lin., linear; Quad., quadratic.

vitamin level. The serum $25(\mathrm{OH}) \mathrm{D}_{3}$ level has been established as a functional indicator of vitamin D by the Food and Nutrition Board [32]. As expected based on a previous study in swine [33], plasma $25(\mathrm{OH}) \mathrm{D}_{3}$ reflected the dietary dose of vitamin D. Lauridsen et al. [14] reported that the $25(\mathrm{OH}) \mathrm{D}_{3}$ level in plasma increased linearly with increasing dietary dose of vitamin D. However, dietary vitamin D treatment exerted no influence on the plasma concentrations of calcium or phosphorus in the gilts, whereas the calcium concentration in the plasma of piglets was influenced by the interaction between supplementation level and day of blood sampling. Zeni et al. [34] reported that the calcium demands during lactation are greater than those during pregnancy. Unfortunately, this experi- 
Table 8. Effects of vitamin supplementation levels in gestation diets on blood profiles of sows in the lactation period

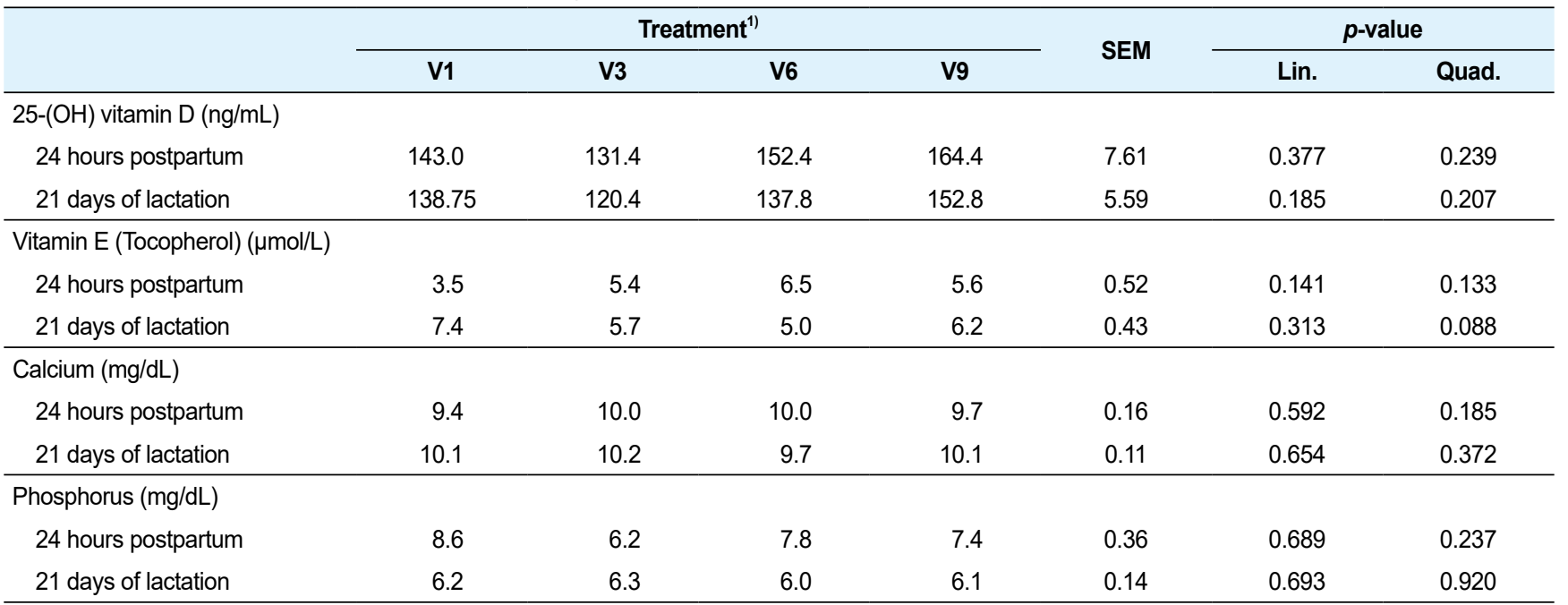

${ }^{1)}$ Treatment: V1, corn-soybean meal (SBM) based diet with 1× National Research Council (NRC, 2012) vitamin requirement; V3, corn-SBM-based diet with 3× NRC (2012) vitamin requirement; V6, corn-SBM-based diet with 6× NRC (2012) vitamin requirement; V9, corn-SBM-based diet with 9× NRC (2012) vitamin requirement.

Lin., linear; Quad., quadratic.

Table 9. Effects of vitamin supplementation levels in gestation diets on blood profiles of piglets in the lactation period

\begin{tabular}{|c|c|c|c|c|c|c|c|}
\hline & \multicolumn{4}{|c|}{ Treatment $^{1)}$} & \multirow{2}{*}{ SEM } & \multicolumn{2}{|c|}{$p$-value } \\
\hline & V1 & V3 & V6 & V9 & & Lin. & Quad. \\
\hline \multicolumn{8}{|l|}{ 25-(OH) vitamin $\mathrm{D}(\mathrm{ng} / \mathrm{mL})$} \\
\hline 24 hours postpartum & $40.3^{b}$ & $30.1^{\mathrm{b}}$ & $31.8^{\mathrm{b}}$ & $141.5^{\mathrm{a}}$ & 11.35 & 0.063 & 0.062 \\
\hline 21 days of lactation & $18.1^{\mathrm{b}}$ & $15.5^{\mathrm{b}}$ & $16.4^{\mathrm{b}}$ & $30.2^{\mathrm{a}}$ & 2.02 & 0.011 & 0.022 \\
\hline \multicolumn{8}{|c|}{ Vitamin E (Tocopherol) $(\mu \mathrm{mol} / \mathrm{L})$} \\
\hline 24 hours postpartum & $4.5^{\mathrm{B}}$ & $12.4^{\mathrm{A}}$ & $12.8^{\mathrm{A}}$ & $12.4^{\mathrm{A}}$ & 1.11 & 0.009 & 0.017 \\
\hline 21 days of lactation & 12.8 & 10.8 & 9.6 & 11.4 & 0.72 & 0.499 & 0.188 \\
\hline \multicolumn{8}{|l|}{ Calcium (mg/dL) } \\
\hline 24 hours postpartum & 10.6 & 10.1 & 9.7 & 10.0 & 0.16 & 0.238 & 0.190 \\
\hline 21 days of lactation & 11.0 & 11.4 & 10.9 & 11.0 & 0.12 & 0.519 & 0.876 \\
\hline \multicolumn{8}{|l|}{ Phosphorus (mg/dL) } \\
\hline 24 hours postpartum & 5.7 & 8.0 & 5.4 & 6.5 & 0.40 & 0.838 & 0.674 \\
\hline 21 days of lactation & 9.6 & 9.6 & 9.5 & 9.5 & 0.24 & 0.817 & 0.967 \\
\hline
\end{tabular}

${ }^{1}$ Treatment: V1, corn-soybean meal (SBM)-based diet with $1 \times$ National Research Council (NRC, 2012) vitamin requirement; V3, corn-SBM-based diet with 3× NRC (2012) vitamin requirement; V6, corn-SBM-based diet with 6× NRC (2012) vitamin requirement; V9, corn-SBM-based diet with 9× NRC (2012) vitamin requirement.

$A, B$ Means with different capital letter superscripts in the same row are significantly different $(p<0.01)$.

${ }^{a, b}$ Means with different small letter superscripts in the same row are significantly different $(p<0.05)$.

Lin., linear; Quad., quadratic.

ment were unable to analyze the concentration of vitamin $\mathrm{D}$ in the milk of sows, but the concentration of $25(\mathrm{OH}) \mathrm{D}_{3}$ in cow milk is known to increase with cholecalciferol treatment before parturition [35]. Shelton et al. [17] reported that the plasma $\alpha$-tocopherol level in suckling pigs increased with increasing level of vitamin $\mathrm{E}$ in the diet of sows. Mahan et al. [16] reported increased $\alpha$ -tocopherol concentrations in colostrum and milk with increasing levels of dietary vitamin $\mathrm{E}$ supplementation. As neonatal pigs are deficient in vitamin $\mathrm{E}$, the concentration of $\alpha$-tocopherol increas- es in pigs nursed by the sow [31], and decreases in postweaning [36].

\section{Conclusions}

There were no significant differences in growth performance or reproductive performance during the gestation or lactation period, although the serum vitamin concentrations of piglets increased with increasing levels of vitamin supplementation in the diet of gestating sows. In conclusion, the current NRC (2012) vitamin 
requirement is sufficient for gestating sows, and additional vitamin supplementation of the diet did not show any beneficial effects for gestating and lactating sows.

\section{Competing interests}

We certify that there are no conflicts of interest regarding the material presented in this manuscript.

\section{Funding sources}

This work was carried out with the support of the Cooperative Research Program for Agriculture Science \& Technology Development (Project No. PJ011617), Rural Development Administration, Korea.

\section{Acknowledgements}

Not applicable.

\section{Availability of data and material}

Upon reasonable request, the datasets of this study can be available from the corresponding author.

\section{Authors' contributions}

Conceptualization: Kim YY.

Data curation: Jeong JH.

Formal analysis: Han TH, Chung WL.

Methodology: Jeong JH, Fang LH.

Software: Jeong JH, Han TH.

Validation: Hong JS.

Investigation: Kim YY.

Writing - original draft: Jeong JH, Fang LH.

Writing - review \& editing: Kim YY.

\section{Ethics approval and consent to participate}

All experimental procedures involving animals were conducted in accordance with the Animal Experimental Guidelines of the Seoul National University Institutional Animal Care and Use Committee (SNUIACUC; SNU-160819-11).

\section{ORCID}

Jae Hark Jeong

Jin Su Hong

Tae Hee Han

Lin Hu Fang

Woo Lim Chung

Yoo Yong Kim

\section{References}

1. DeLuca HF. Vitamin D. In: DeLuca HF, editor, Handbook of lipid research. New York, NY: Plenum Press; 1978. p.69-132.

2. Halloran BP, Barthell E, DeLuca HF. Vitamin D metabolism during pregnancy and lactation in the rat. Proc Natl Acad Sci. 1979;76:5549-53.

3. Wuryastuti H, Stowe HD, Bull RW, Miller ER. Effects of vitamin $\mathrm{E}$ and selenium on immune responses of peripheral blood, colostrum, and milk leukocytes of sows. J Anim Sci. 1993;71:2464-72.

4. Tarin JJ, Perez-Albala S, Pertusa JF, Cano A. Oral administration of pharmacological doses of vitamins $\mathrm{C}$ and $\mathrm{E}$ reduces reproductive fitness and impairs the ovarian and uterine functions of female mice. Theriogenology. 2002;57:1539-50.

5. Stuart RL, Kane E. Vitamin E form, source may be important for swine. Feedstuffs. 2004;76:11-4.

6. Pinelli-Saavedra A, Scaife JR. Pre-and postnatal transfer of vitamins $\mathrm{E}$ and $\mathrm{C}$ to piglets in sows supplemented with vitamin E and vitamin C. Live St Prod Sci. 2005;97:231-40.

7. Nelson JS. Pathology of vitamin E deficiency. In: Machlin LJ, editor. Vitamin E - A comprehensive treatise. New York, NY: Marcel Dekker; 1980.p.397-428.

8. Lindemann MD, Cromwell GL, Monegue HJ. Effects of inadequate and high levels of vitamin fortification on performance of weanling pigs. J Anim Sci. 1995;73:16.

9. National Research Council. Nutrient requirements of swine. 10th ed. Washington, DC: National Academy Press; 1998.

10. Boyd RD, Williams N, Allee GL. Segregated parity structure in sow farms to capture nutrition, management and health opportunities. In: Proceedings of the Midwest Swine Nutrition Conference; 2008. Indianapolis, IN. p.45-50.

11. National Research Council. Nutrient requirements of swine. 11th ed. Washington, DC: National Academy Press; 2012.

12. Chae BJ. Effects of dietary vitamins and trace minerals on growth and carcass quality in pigs. Asian-Australas J Anim Sci. 2000;13:243-51.

13. Flohr JR, DeRouchey JM, Woodworth JC, Tokach MD, Goodband RD, Dritz SS. 2016. A survey of current feeding regimens for vitamins and trace minerals in the US swine industry.J Swine Health Prod. 2016;24:290-303.

14. Lauridsen C, Halekoh U, Larsen T, Jensen SK. Reproductive performance and bone status markers of gilts and lactating sows supplemented with two different forms of vitamin D. J Anim Sci. 2010;88:202-13.

15. Flohr JR, Tokach MD, Dritz SS, DeRouchey JM, Goodband $\mathrm{RD}$, Nelssen JL, et al. An evaluation of the effects of added vitamin D3 in maternal diets on sow and pig performance. J 
Anim Sci. 2014;92:594-603.

16. Mahan DC. Effects of dietary vitamin E on sow reproductive performance over a five-parity period. J Anim Sci. 1994;72:2870-9.

17. Shelton NW, Dritz SS, Nelssen JL, Tokach MD, Goodband RD, DeRouchey JM, et al. 2014. Effects of dietary vitamin E concentration and source on sow, milk, and pig concentrations of $\alpha$-tocopherol.J Anim Sci. 2014;92:4547-56.

18. Goldner WS, Stoner JA, Thompson J, Taylor K, Larson L, Erickson J, et al. Prevalence of vitamin D insufficiency and deficiency in morbidly obese patients: a comparison with nonobese controls. Obes Surg. 2008;18:145-50.

19. Emily Fish BS, Gretchen Beverstein NP, Diane Olson RD, Susan Reinhardt RN, Michael Garren MD, Jon Gould MD. Vitamin D status of morbidly obese bariatric surgery patients. J Surg Res. 2010;164:198-202.

20. Kong J, Li YC. Molecular mechanism of 1,25-dihydroxyvitamin D3 inhibition of adipogenesis in 3T3-L1 cells. Am J Physiol Endocrinol Metab. 2006;290:E916-24.

21. Ching S, Kashinkunti S, Niehaus MD, Zinser GM. Mammary adipocytes bioactivate 25-hydroxyvitamin D3 and signal via vitamin D3 receptor, modulating mammary epithelial cell growth. J Cell Biochem. 2011;112:3393-405.

22. Wortsman J, Matsuoka LY, Chen TC, Lu Z, Holick MF. Decreased bioavailability of vitamin D in obesity. Am J Clin Nutr. 2000;72:690-3.

23. Blum M, Dolnikowski G, Seyoum E, Harris SS, Booth SL, Peterson J, et al. Vitamin D3 in fat tissue. Endocrine. 2008;33:90-4.

24. Vinh quoc Lưong, K and Nguyen LTH. The beneficial role of vitamin $\mathrm{D}$ in obesity: possible genetic and cell signaling mechanisms. Nutr J. 2013;12:89.

25. Dourmad JY. Effect of feeding level in the gilt during pregnancy on voluntary feed intake during lactation and changes in body composition during gestation and lactation. Livest Production Sci. 1991;27:309-19.

26. Williams IH, Smits RJ. Body protein losses can be minimised during lactation. In: Batterham ES, editor. Manipulating pig production III. Werribee: Australasian Pig Science Associa- tion; 1991.p.73.

27. Williams IH. Nutritional effects during lactation and during the interval from weaning to oestrus. In: Verstegen MWA, Moughan PJ, Schrama JW, editor. The lactating sow. Wageningen: Wageningen Pers; 1998. p.159-181.

28. Woods SC, Seeley RJ, Porte D, Schwartz MW. Signals that regulate food intake and energy homeostasis. Science. 1998;280:1378-83.

29. Head RH, Williams IH, Batterham ES. Mammogenesis is influenced by pregnancy nutrition. In: Manipulating pig production III. Werribee: Australasian Pig Science Association; 1991.p.33.

30. Head RH, Williams IH. Potential milk production in gilts. In: Hennessy DP, Cranwell PD, editors. Manipulating pig production V, Werribee: Australasian Pig Science Association; 1995. p.134.

31. Mahan DC. Assessment of the influence of dietary vitamin $\mathrm{E}$ on sows and offspring in three parities: reproductive performance, tissue tocopherol, and effects on progeny. J Anim Sci. 1991;69:2904-17.

32. Food and Nutrition Board. Dietary reference intakes for calcium, phosphorus, magnesium, vitamin D, and fluoride. Standing Committee on the Scientific Evaluation of Dietary Reference Intakes, Washington, DC: Inst. Medicine, National Academies Press; 1997.

33. Wilborn BS, Kerth CR, Owsley WF, Jones WR, Frobish LT. Improving pork quality by feeding supranutritional concentrations of vitamin D3.J Anim Sci. 2004;82:218-24.

34. Zeni SN, Gregorio SD, Mautalen C. Bone mass changes during pregnancy and lactation in the rat. Bone. 1999;25:681-5.

35. Hollis BW, Lambert PW, Horst RL. Factors affecting the antirachitic sterol content of native milk. In: Holick MF, Gray TK, Anast CS, editor. Perinatal calcium and phosphorus metabolism. Amsterdam: Elsevier; 1983. p.157-82.

36. Lauridsen C, Jensen SK. Influence of supplementation of allrac- $\alpha$-tocopherol acetate preweaning and vitamin $\mathrm{C}$ postweaning on $\alpha$-tocopherol and immune responses in piglets. J Anim Sci. 2005;83:1274-86. 
